\title{
A produção de cereais em uma propriedade no município de Chapecó - SC
}

\author{
The production of grain in small properties: a case study in the city of Chapecó - SC, Brazil
}

\author{
Odimar Ozelame ${ }^{I}$ Tanice Andreatta ${ }^{I I}$
}

\section{RESUMO}

\begin{abstract}
O presente artigo aborda uma análise da produção de cereais em uma propriedade rural no município de ChapecóSC. A coleta dos dados foi realizada considerando o cultivo da soja, do trigo e do milho, durante as safras 2008/2009, 2009/ 2010 e 2010/2011. Foram analisados os indicadores referentes aos custos de produção, indicadores técnicos e indicadores econômicos. Como resultado, identificou-se que os insumos são responsáveis pela maior parte dos custos nos três cultivos analisados, o cultivo da soja apresentou maior lucratividade, já o trigo apresentou prejuízo em duas safras agrícolas, das três consideradas. A lucratividade média no período foi significativa, mas o retorno do investimento pode ser considerado baixo $(6,8 \%$ ao ano). Considerando o capital investido na atividade (terra + máquinas e construções + custeio) pela lucratividade do período analisado, verifica-se a necessidade de 57,28 anos para recuperar esse capital. Constatou-se que o apego a terra, à tradição e à satisfação pessoal, são fatores que contribuem para explicar a permanência desse produtor no meio rural, mesmo quando determinadas atividades se mostram inviáveis ou com margens de lucratividade baixas.
\end{abstract}

Palavras-chave: custos de produção, análise econômica, indicadores técnicos.

\footnotetext{
ABSTRACT

This article approaches an analysis of grain production on a farm in the city of Chapecó-SC, Brazil. Data collection was held, considering the crops of soybeans, wheat and corn crops during the 2008/2009, 2009/2010 and 2010/ 2011 harvests. Production costs, technical and economic indicators were analyzed. As a result, it was identified that the raw materials are responsible for most of the costs analyzed in
}

\begin{abstract}
the last three crops, the cultivation of soybeans showed the highest profitability, wheat however, showed losses in two growing seasons of the three considered. The average profitability in the period was substantial, but the return on investment can be considered low (6.75\% per year). Taking into consideration the capital invested in the activity (land + machinery and construction + costing) for the profitability of the analyzed period, it was verified that there is a need of 57.28 years to recover that amount. Frequently, it was found that attachment to land, tradition and personal satisfaction are factors that contribute in explaining the permanence of producers in rural areas, even when certain activities prove to be unfeasible or yield low profit margins.
\end{abstract}

Key words: cost of production, economic analysis, technical indicators.

\section{INTRODUÇÃO}

Historicamente, a agricultura possui um papel relevante no processo de desenvolvimento do Brasil. A política de modernização da agricultura brasileira, implantada a partir da década de 1970, implicou um incremento significativo em área ocupada, assim como na produção/produtividade de grãos. O crédito rural subsidiado, a presença das instituições de pesquisa, a presença efetiva da assistência técnica e a Política Geral de Preços Mínimos (PGPM) possibilitaram a expansão dos cultivos de maneira efetiva (GRAZIANO DASILVA, 1996).

\footnotetext{
'Sementes Coxilha Rica, Avenida Getúlio Vargas, 268 N, Sala 01, 89801-000, Chapecó, SC, Brasil. E-mail: oozelame@ hotmail.com. Autor para correspondência.

"Universidade Federal do Pampa (UNIPAMPA), Campus Dom Pedrito, Dom Pedrito, RS, Brasil.
} 
As cadeias do trigo e do milho, mas sobretudo a da soja, ocupam uma posição importante na configuração do PIB do Agronegócio brasileiro. Esses três produtos, em maior ou menor grau, estão relacionados com o desenvolvimento agrícola do Sul do Brasil. Em nível de Brasil, o estado de Santa Catarina, no ano de 2010, ocupava o nono lugar na produção de grãos. A Microregião de Chapecó é a primeira colocada na produção de milho (616.622 toneladas) e ocupa o terceiro lugar na produção de soja (205.496 toneladas) e de trigo (53.319 toneladas) (CEPA, 2010). Esses produtos, juntamente com a criação de suínos e aves, têm uma relação estreita com a colonização do município de Chapecó.

A estrutura fundiária de Chapecó é constituída por pequenas propriedades. Cerca de $70 \%$ delas possuem área inferior a 20 ha; $21,88 \%$ (21 a 50ha); $4,24 \%$ de 51 a 100 ha e $2,92 \%$ acima de 100 ha, totalizando 1.791 propriedades (IBGE, 2007). É observada uma forte presença de mão-de-obra familiar e alta utilização do fator de produção terra.

As mudanças ocorridas na economia mundial e o avanço tecnológico têm causado consequências em todas as áreas. No setor agropecuário, a abertura da economia brasileira ao exterior implicou uma série de desafios aos produtores. Nesse contexto, no segmento de commodities agrícolas, a lucratividade depende da eficiência e da eficácia dos produtores e das economias de escala, em um ambiente de mercado marcado pela livre concorrência, pelo fim do crédito subsidiado e pela instabilidade de preços. Em linhas gerais, os impactos recaem de forma mais incisiva sobre pequenos agricultores, produtores de commodities.

Nesse contexto, o objetivo do trabalho é realizar uma análise da produção de grãos em uma propriedade rural no município de Chapecó-SC. Também objetiva-se relacionar os custos de produção e a lucratividade dos cultivos do trigo, soja e milho, com o intuito de considerar a perspectiva da produção de cereais em pequenas propriedades.

A produção de commodities em pequenas propriedades

A natureza da ocupação agrícola, a combinação entre a propriedade, o gerenciamento do estabelecimento, a natureza do trabalho e a sucessão são elementos que, muitas vezes, são mais importantes que a noção da "maximização dos lucros". A funçãoobjetivo de um negócio familiar pode ser composta por um número significativo de objetivos e a maximização dos lucros pode não ser o principal deles (GASSON \& ERRINGTON, 1993).
Na produção agrícola, a terra é um elemento chave, cumpre muitas funções e, muitas vezes, ultrapassa a esfera da produção, da reserva de valor e/ ou da especulação. MAUREL (1998) expõe que o fator "terra", no contexto do rural, possui muitos significados, que vão além das relações mercantis. Assim, as formas de acesso e as relações sociais envolvidas também são aspectos que indicam tendências ao longo do tempo. O simbolismo, ou a identidade do agricultor com a terra, também é um fator relevante para compreender a lógica dos agricultores (GASSON \& ERRINGTON, 1993; MAUREL, 1998).

Assim, o apego a terra, às questões culturais, a identificação com as atividades agrícolas, as características dos agricultores são elementos que contribuem para explicar a permanência de agricultores atuando na agricultura, ainda que, muitas vezes, estes operem com prejuízo ou rentabilidade muito baixa (GASSON \& ERRINGTON, 1993).

Independente do tamanho do estabelecimento, no contexto econômico atual, os custos de produção precisam ser monitorados (MARION et al., 2009). Diante das vulnerabilidades associadas aos aspectos produtivos, da complexificação das operações financeiras e da dificuldade de sustentar as margens de lucratividade, a gestão de custos tem se tornado uma necessidade para o planejamento das atividades e para a tomada de decisão dos agricultores. Tal ferramenta é muito importante inclusive para as pequenas propriedades, que não podem se beneficiar da economia de escala, portanto os agricultores precisam ser criteriosos na escolha dos sistemas de produção e na sua forma de implementação.

\section{MATERIAL E MÉTODOS}

A pesquisa consiste em um estudo em uma propriedade rural do município de Chapecó-SC, considerado o maior município da Região Oeste Catarinense. A coleta dos dados foi realizada através de entrevistas com o produtor, no mês de janeiro de 2012. Na primeira entrevista, o produtor relatou a história da propriedade e sua trajetória na agricultura; na segunda entrevista, o foco foram os aspectos técnicos e produtivos; e, na terceira, o produtor relatou os aspectos econômicos. Convém ressaltar que o produtor mantém o acompanhamento sistemático das atividades agrícolas e disponibilizou as planilhas eletrônicas e relatórios referentes às atividades da propriedade. $\mathrm{O}$ monitoramento das atividades compreende três safras agrícolas (2008/2009, 2009/2010 e 2010/2011).

A área da propriedade compreende 99 hectares, destinada à produção de cereais. A produção 
é baseada no sistema de plantio direto a mais de 10 anos, utiliza somente mão-de-obra familiar e dispõe de área e um parque de máquinas próprias.

Para a análise dos custos de produção e da economicidade dos cereais, levou-se em consideração a metodologia descrita pelos autores HOFFMANN et al. (1987).

Dessa forma, foi priorizada a identificação e quantificação dos principais componentes para a formação do custo de produção (custo fixo, custo variável e custo total). Também foram analisados os indicadores técnicos (produção por área e produtividade) e indicadores econômicos (margem bruta, lucratividade e custo de oportunidade).

A partir dos componentes de uso de insumos e operações de máquinas por unidade de produção, foram construídos os indicadores abaixo relacionados, para serem analisados por atividade agrícola, entre as atividades, e também para a constituição de um cenário sobre o futuro das pequenas propriedades.

a) Formação dos custos de produção: Custos variáveis: são os custos que se incorporam totalmente aos produtos, depende das quantidades produzidas. Insumos: somatório dos insumos utilizados no ciclo de produção; Despesas Operacionais: somatório das despesas utilizadas com máquinas e equipamentos no ciclo de produção; Outras despesas: despesas previdenciárias, seguros, assistência técnica e juros de custeio.

- Custos fixos: custos que não se incorporam no produto no curto prazo.

- Custo total: somatório dos custos fixos e custo variável.

b) Indicadores econômicos: Receita bruta: quantidade produzida x preço de comercialização; Receita líquida: receita bruta, deduzido o custo total; Custo variável médio: custo variável dividido pela produção; Custo total médio: custo total dividido pela produção; Lucro médio $(\mathrm{R} \$ / \mathrm{sc})$ : receita líquida dividida pelo valor da produção.

Os dados foram sistematizados e analisados em planilhas do Microsoft Excel. Convém ressaltar que a parte do custo de produção das atividades é referente à 1 ha, os demais se referem a sua totalidade.

\section{RESULTADOS E DISCUSSÃO}

a) Formação do custo de produção dos cultivos do trigo, soja e milho - safras 2008/2009, 2009/2010 e 2010/ 2011

A maior parte dos componentes dos custos de produção do trigo, da soja e do milho é configurada pelos custos variáveis. No cultivo do trigo, nas três safras analisadas, variaram entre $91 \%$ e $95 \%$; no cultivo da soja, a variação compreende o intervalo de $79 \%$ e
$82 \%$. Já no cultivo do milho, os custos variáveis correspondem ao intervalo de $83 \%$ e $86 \%$. Na composição dos custos variáveis, nos três cultivos, os grupos dos insumos (sementes, herbicidas, inseticidas, fungicidas) são os mais representativos, seguido das operações agrícolas.

O fertilizante é o insumo de maior participação no cultivo do trigo, soja e milho. Apesar de sua alta participação na composição dos custos, NETO \& FANCELLI (2000) o descreve como sendo o principal insumo responsável pela alta produtividade, seguido do controle de doenças, insetos e plantas daninhas.

Ao analisar as fontes de adubação química utilizadas atualmente, verificou-se que são praticamente as mesmas utilizadas desde o período da modernização da agricultura. A configuração dos preços desses insumos está associada à estrutura de mercado, que denota um forte poder da indústria de fertilizantes na formação dos preços. De forma empírica, trabalha-se com a tese de que redução no valor dos fertilizantes estimularia o aumento na quantidade de adubação a ser utilizado nos cereais, permitindo aumento de produção e/ou da produtividade.

As despesas operacionais requerem uma atenção especial, devido ao aumento da sua participação na ordem de 20\% (Figura 1) do custo total em relação aos últimos três anos. Esse aumento tem sido motivado, principalmente pelo valor das máquinas agrícolas e pelos custos de manutenção destas (óleo diesel e lubrificantes).

Em linhas gerais, esses resultados servem como indicadores para demonstrar que os insumos representam a maior parte dos custos de produção. Por outro lado, em larga medida, dependendo do perfil dos solos, a produtividade desses cultivos depende da utilização destes insumos. Nesse sentido, a decisão adequada no ajuste das quantidades, relacionando-as o custo-benefício, depende de um controle sistemático dos custos de produção.

b) Análise econômica da produção de cereais

A análise econômica pode ser resumida através da multiplicação de dois fatores, ou seja, um de produção (produtividade) e outro de mercado (preço do produto). A partir daí, é possível verificar em que grau foram recuperados os custos despendidos na produção de cereais no período.

O cultivo do trigo, nas últimas três safras analisadas, apresentou um resultado técnico significativo (a produtividade média de 52,66 sacas ha ${ }^{-1}$ ). $\mathrm{Na}$ última safra, os resultados foram consideravelmente acima da média dos últimos anos, obtidos, sobretudo, por condições climáticas favoráveis. 


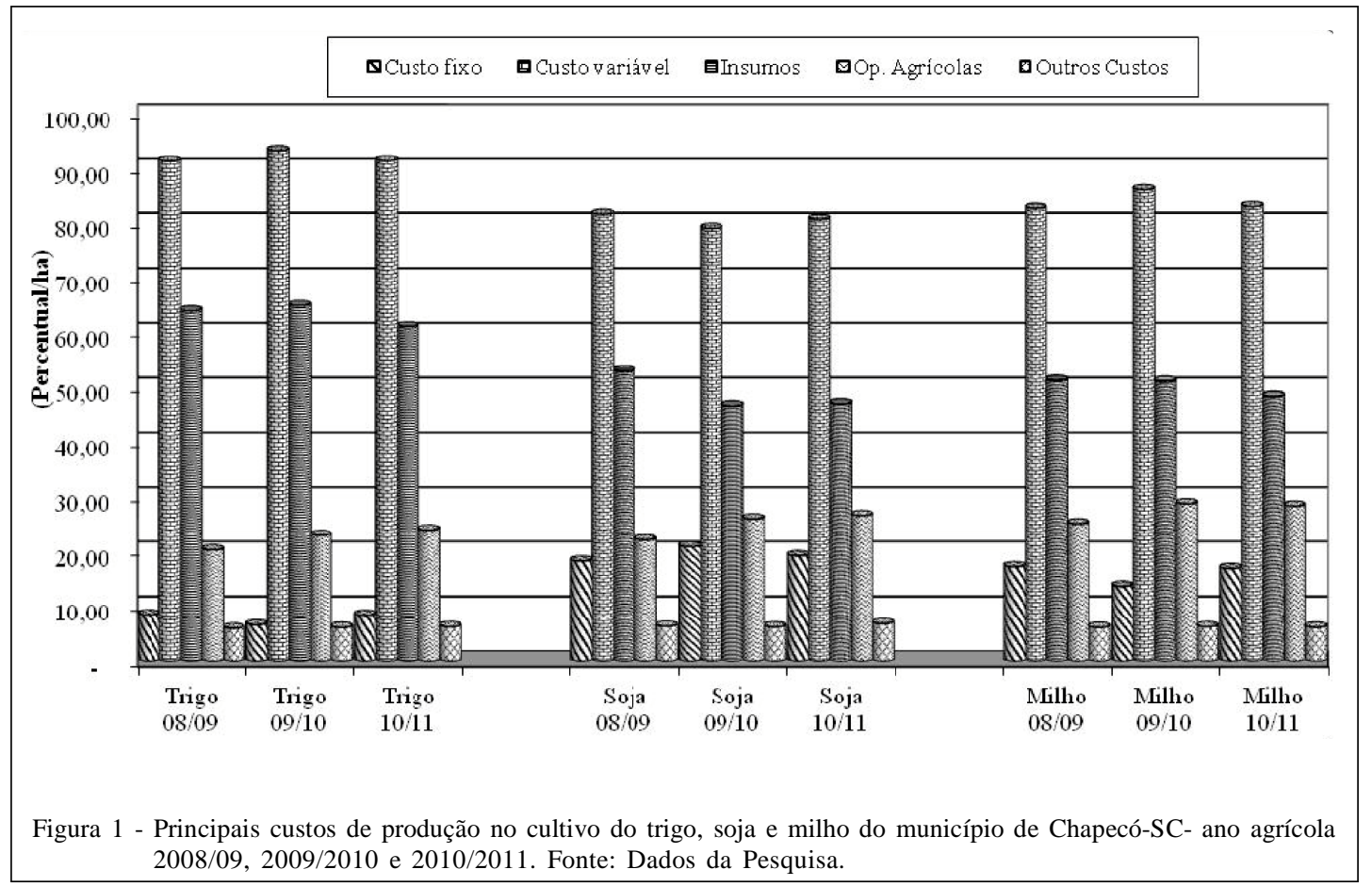

O cultivo do trigo apresentou margens positivas apenas na safra 2010/2011, na ordem de R \$ 16,66 por hectare (Tabela 1). Resultados semelhantes foram encontrados por MAGGIAN et al (2010) ao analisar a rentabilidade do trigo na região de Guarapuava (PR) e por HIRAKURI \& LAZZAROTTO (2010) em um estudo na região de Londrina (PR). Assim, constata-se que a rentabilidade negativa do trigo não é um aspecto isolado para determinadas regiões ou mesmo devido ao tamanho da área cultivada. Persistindo esse cenário, provavelmente uma das medidas a ser adotada pelos produtores será a substituição e/ou redução nas área de plantio de trigo no Sul do Brasil.

A soja também demonstrou resultado técnico expressivo no período analisado. A menor produtividade foi registrada na safra 2008/09, em larga medida, decorrente de uma estiagem na região, ocorrida no final de janeiro até meados de abril. Essa estiagem incidiu sobre a fase reprodutiva da oleaginosa e resultou em uma quebra de produtividade na ordem de $15 \%$.

A soja é uma das commodities cultivadas desde a colonização da região (MIOR, 2005), mantendo-se historicamente como atividade de baixo risco de produção e com lucratividade positiva. No período analisado, foi obtida uma lucratividade média $\mathrm{ha}^{-1}$ de $\mathrm{R} \$ 490,75$, apresentando uma variação de $\mathrm{R} \$$ 328,62 na safra 2009/2010 para $R \$ 725,76$ na safra 2010/
2011 (Tabela 1). Na safra 2009/2010, registrou-se uma baixa significativa do valor de mercado da soja, situação que redundou em uma menor lucratividade no período.

O cultivo da soja apresentou maior margem de lucratividade quando comparado ao milho, embora ambas apresentassem resultados positivos durante o período analisado. Além do clima favorável, é preciso considerar a longa trajetória dos agricultores, haja vista que são os dois principais cultivos utilizados desde o período da colonização do município e da região Oeste Catarinense, ainda que tenha ocorrido mudança no contexto tecnológico, econômico e político, além de mudanças nas margens de produção e comercialização (MIOR, 2005).

O milho foi um cultivo que também apresentou resultados expressivos nessas últimas safras, perfazendo uma produtividade média nas três safras analisadas de 144,66 sacas ha-1. Os resultados produtivos são considerados acima da média do município, refletindo, entre outros fatores, o alto pacote tecnológico e uma regularidade nas chuvas. Convém ressaltar que as produtividades médias registradas na propriedade estão acima das médias do município.

A receita líquida total da propriedade no período corresponde a uma participação de $24,20 \%$ da safra 2008/09, 20,47\% da safra 2009/2010 e 55,33\% da safra 2010/2011, perfazendo um total de $\mathrm{R} \$ 107.462,05$. A lucratividade média por hectare cultivado, 
considerando os cultivos de verão e inverno, equivale a $\mathrm{R} \$ 316,82$. A soja foi o cultivo com a maior participação na lucratividade da propriedade (Tabela 1).

Convém ressaltar que, para realizar a exploração da atividade agrícola com a produção de trigo, soja e milho, o produtor dispõe de uma infraestrutura direta de máquinas avaliadas em um valor de $\mathrm{R}$ \$ 240.000,00; de instalações no valor de $\mathrm{R} \$$ 15.000,00, totalizando R \$255.000,00, e um capital de giro para custear a produção no valor de $\mathrm{R} \$ 275.672,92$.

A configuração dessa propriedade, desde os aspectos técnico-produtivos até os aspectos econômicos financeiros, permite obter, em contrapartida, uma receita líquida anual de $\mathrm{R} \$ 35.820,68$, ou receita líquida no período analisado de $\mathrm{R} \$ 107.462,05$. Antes de qualquer reflexão, é necessário considerar que o período analisado pode ser considerado um período favorável, no que se refere aos aspectos mercadológicos e climáticos. A tendência é a de que, no longo prazo, esses fatores sofram alterações significativas.

Nesse contexto, na propriedade analisada, foi apurada uma lucratividade significativa, mas o retorno do investimento pode ser considerado baixo. O retorno apresenta uma margem de $6,75 \%$ do capital investido anualmente na produção de cereais $\left(0,5625 \mathrm{mês}^{-1}\right)$. Ao traçar uma comparação desse resultado com os do mercado financeiro, verifica-se um desempenho inferior ao que pode ser obtido, por exemplo, com o da caderneta de poupança. Assim, questiona-se a perspectiva da propriedade no longo prazo. Quais as razões do agricultor permanecer atuando no cultivo de grãos?

c) Cenários para produção de cereais em pequenas propriedades

O valor da terra destinada para produção de cereais na região de Chapecó-SC está avaliado em torno de $\mathrm{R} \$ 18.000,00$ por hectare (aproximadamente 1000 sacas de soja o alqueire); multiplicado pela área de cultivo, obteremos o valor de R\$1.782.000,00, que é o valor do imóvel analisado.

De forma hipotética, ao fazer algumas simulações como, por exemplo, dividir o valor de um (1) hectare pela receita líquida média de um (1) hectare, verifica-se a necessidade de 49,7 anos para conseguir recuperar o capital investido. Outro dado hipotético que permite fazer inferências pode ser a divisão da receita líquida anual da propriedade pelo valor de 1(um) hectare. Com base nesse cálculo, pode-se adquirir 1,99 hectares ano ${ }^{-1}$, necessitando de 12 anos agrícolas para conseguir adquirir 10 alqueires de terra nesse cenário. Outro exemplo: ao dividir o capital investido na atividade (terra + máquinas e construções + custeio) pela lucratividade do período analisado, verifica-se a necessidade de 57,28 anos para recuperar esse capital. Novamente, questiona-se: esse é um resultado interessante, do ponto de vista de uma análise exclusivamente econômica?

Tabela 1 - Principais indicadores econômicos do cultivo do trigo, soja e milho no município de Chapecó-SC - ano agrícola 2008/2009, 2009/2010 e 2010/2011.

\begin{tabular}{|c|c|c|c|c|c|c|c|c|}
\hline Cultura & Safra & Area (ha) & Prod. (SC/ha) & Preço venda (R\$/sc) & Receita bruta & Custo total & Receita líquida & $\%$ \\
\hline Trigo & $2008 / 2009$ & 66 & 51 & 26,67 & $89.771,22$ & $102.059,15$ & $(12.287,93)$ & - \\
\hline Soja & $2008 / 2009$ & 66 & 48 & 43,52 & $137.871,36$ & $110.291,19$ & $27.580,17$ & 72,01 \\
\hline Milho & $2008 / 2009$ & 33 & 138 & 20,66 & $94.085,64$ & 83.367 .25 & $10.718,39$ & 27,99 \\
\hline \multicolumn{2}{|c|}{ Sub Total 1} & 165 & & & $321.728,22$ & $295.717,59$ & $26.010,63$ & 100,00 \\
\hline Trigo & $2009 / 2010$ & 66 & 50 & 26,05 & $85.965,00$ & $94.285,21$ & $(8.320,21)$ & - \\
\hline Soja & $2009 / 2010$ & 66 & 54 & 31,06 & $110.697,84$ & $89.008,47$ & $21.689,37$ & 71,54 \\
\hline Milho & $2009 / 2010$ & 33 & 146 & 17,43 & $83.977,74$ & $75.350,49$ & $8.627,25$ & 28,46 \\
\hline \multicolumn{2}{|c|}{ Sub Total 2} & 165 & & & $280.640,58$ & $258.644,16$ & $21.996,42$ & 100,00 \\
\hline Trigo & $2010 / 2011$ & 66 & 57 & 26,00 & $97.812,00$ & $96.712,23$ & $1.099,77$ & 1,85 \\
\hline Soja & $2010 / 2011$ & 66 & 55 & 40,00 & $145.200,00$ & $97.299,72$ & $47.900,28$ & 80,57 \\
\hline Milho & $2010 / 2011$ & 33 & 150 & 18,00 & $89.100,00$ & $78.645,05$ & $10.454,95$ & 17,58 \\
\hline \multirow{2}{*}{\multicolumn{2}{|c|}{$\begin{array}{l}\text { Sub Total } 3 \\
\text { Total Geral }(1+2+3)\end{array}$}} & 165 & & & $332.112,00$ & $272.657,00$ & $59.455,00$ & 100,00 \\
\hline & & & & & $934.480,80$ & $827.018,75$ & $107.462,05$ & \\
\hline
\end{tabular}

Fonte: Dados da Pesquisa. 
Em linhas gerais, esses números significam o resultado de praticamente uma vida de trabalho do produtor num cenário positivo, para, na melhor das condições, atingir essa estrutura de produção de cereais com essas semelhanças. Cabe ressaltar, especificamente neste caso, que a terra é oriunda de um processo de herança familiar. $\mathrm{O}$ produtor somente realizou a aquisição das máquinas e formou o capital de giro. É importante ressaltar que o produtor não utiliza financiamento bancário para o custeio das atividades.

Em termos de lucratividade, o valor apurado no período com o cultivo de cereais foi de $\mathrm{R} \$ 107.462,05$, ou R \$ 2.985,05 mensais (aproximadamente seis salários mínimos/mês). Se for considerada uma família rural composta por quatro indivíduos, por exemplo, isso representa 1,4 salários mínimos mensais, por indivíduo. Nesse contexto, percebe-se que a grande maioria das propriedades com essa configuração terá dificuldade de realizar a aquisição de novas áreas de terras. Considerando que a propriedade analisada tenda a estar acima da média, em termos de produção e investimentos, a probabilidade de que o cenário da produção de cereais em propriedades menores que a analisada tenda a ser menos lucrativo, em muitos casos, inviável.

As rendas agrícolas decrescentes, a baixa remuneração da mão de obra familiar, a penosidade do trabalho agrícola, a dificuldade para realizar novos investimentos são fatores que também afetam a sucessão e a transmissão do patrimônio familiar (SPANEVELLO, 2008). Na região de Chapecó-SC, a grande maioria das propriedades da região foi adquirida pelos pais e repassada para os filhos que atualmente estão conduzindo a propriedade. No entanto, diante desses resultados, visualiza-se um período de grandes dificuldades e incertezas no que se refere à identificação de possíveis sucessores nas propriedades e, por consequência, da continuidade dessas propriedades.

Quando questionado sobre as motivações para permanecer na agricultura, o produtor elencou fatores como o apego a terra, a satisfação pessoal de atuar na agricultura, a questão cultural, o conhecimento tácito da produção de grãos. Esses aspectos, muitas vezes pouco considerados nas análises econômicas, são propulsores da permanência de agricultores em atividades que apresentam lucratividades baixas, e até mesmo negativas.

\section{CONCLUSÃO}

A partir dos cálculos de custos de produção e lucratividade, em linhas gerais, pode-se vislumbrar um cenário pessimista para a cultura do trigo. No entanto, configura-se cenário favorável para as culturas da soja e do milho, que apresentaram margens positivas e expressivas no período. Os maiores incrementos de lucratividade foram ocasionados mais pelo comportamento dos preços dos produtos analisados do que pela produtividade. Também é preciso considerar que, salvo a safra 2008/2009, em que foi registrado um período de estiagem, nas outras duas safras, as condições climáticas foram favoráveis, o que contribuiu para uma produtividade acima da média.

Em se tratando do meio rural, é preciso considerar que a terra, muitas vezes, ultrapassa a questão única e exclusivamente da rentabilidade. Elementos como a tradição e satisfação pessoal contribuem para explicar a permanência de produtores no meio rural, mesmo quando determinadas atividades se mostram inviáveis ou apresentam rentabilidade baixa.

Apesar do cenário de dificuldades, estas atividades desempenharam e continuam desempenhando um papel muito importante na economia da região. Nesse contexto, é cada vez mais importante a incorporação de mecanismos de política agrícola que proporcionem um cenário de maior estabilidade no setor agropecuário, principalmente para os pequenos produtores. Tal situação seria uma espécie de segurança para os produtores desempenharem a produção, além de usufruir de melhor qualidade de vida e bem estar social.

\section{REFERÊNCIAS}

BRASIL. Lei $n^{\circ} \mathbf{8 . 6 2 9}$, de 25 de fevereiro de 1993 . Disponível em: <http://www.planalto.gov.br/ccivil_03/leis/ 18629.htm>. Acesso em: ago. 2012.

CEPA (Centro de Socioeconomia e Planejamento Agrícola). Síntese Anual da Agricultura de Santa Catarina 2009-2010. Disponível em: <http://cepa.epagri.sc.gov.br/Publicacoes/ Sintese_2010/sintese\%202010_inteira.pdf>. Acesso em: ago. 2012.

GASSON, R.; ERRINGTON, A. The farm family business. Wallingford: CAB International, 1993. 304 p.

GRAZIANO DA SILVA, J. A nova dinâmica da agricultura brasileira. Campinas: Unicamp-Instituto de Economia, 1996. 217 p.

HIRAKURI, M.H; LAZZAROTTO, J.J. Análise de cenários para a produção de trigo safra 2010: Estudo de caso para a região Londrina-PR. In: CONGRESSO DA SOCIEDADE BRASILEIRA DE ECONOMIA, SOCIOLOGIA E ADMINISTRAÇÃO RURAL (SOBER), 68., 2010, Campo Grande, MS. Anais... Campo Grande: Universidade Católica Dom Bosco (UCDB). 12 p.

HOFFMANN, R et al. Administração da empresa agrícola. 5.ed. São Paulo: Pioneira, 1987. 325 p.

IBGE (Instituto Brasileiro de Geografia e Estatística). Censo Demográfico 2007. Rio de Janeiro, 2007. Disponível em: <http:/www.ibge.gov.br>. Acesso em: fev. 2011. 
MARION, J.C. et al. Administração de custos na agropecuária. São Paulo: Atlas, 2009. 168 p.

MAGGIAN, R.C. et al. Análise da rentabilidade da cultura do trigo na região de Guarapuava-PR. In: CONGRESSO DA SOCIEDADE BRASILEIRA DE ECONOMIA, SOCIOLOGIA E ADMINISTRAÇÃO RURAL (SOBER), 68, 2010, Campo Grande, MS. Anais... Campo Grande: Universidade Católica Dom Bosco (UCDB). 18 p.

MIOR, L.C. Agricultores familiares, agroindústrias e redes de desenvolvimento. Chapecó: Argos, 2005. 338 p.
NETO, D.D.; FANCELLI, A.L. Produção de milho. Guaíba: Agropecuária, 2000. $360 \mathrm{p}$.

MAUREL, M.C. Das trajetórias às estratégias fundiárias. In: LAMARCHE, H. (Org.). A agricultura familiar: comparação internacional. Do mito à realidade. Campinas: UNICAMP, 1998. p. 89-117.

SPANEVEllo, R. M. A dinâmica da sucessão na agricultura familiar. 2008. 236 p. Tese (Doutorado em Desenvolvimento Rural) - Programa de Pós Graduação em Desenvolvimento Rural, Universidade Federal do Rio Grande do Sul, Porto Alegre, RS. 